TABLE IV-Causes of failure to donate for 29 potential organ donors

\begin{tabular}{lc}
\hline Cause of failure & $\begin{array}{r}\text { No of } \\
\text { cases }\end{array}$ \\
\hline Medical: & \\
Hypotension & 8 \\
Sepsis & 2 \\
Renal failure & 2 \\
Organ trauma & 1 \\
Consent: & \\
Denied by coroner & 8 \\
Denied by relative & 5 \\
Not requested & 3 \\
\hline
\end{tabular}

The age criteria for donations prevented the use of two livers and four hearts.

Twenty nine subjects failed to donate any organs (table IV). This was due to medical contraindications in 13 (profound hypotension, sepsis, trauma, or renal failure). In eight cases the injuries leading to brain stem death resulted in serious criminal charges being brought against another person. In such circumstances the coroner felt unable to grant permission for organ donation. There were five cases in which the relatives refused permission: in three they thought that the patient had "been through enough," in one the patient had expressed a wish not to donate organs, and in one the relatives had doubts about donation. Consent was not requested in only three.

\section{Discussion}

The shortage of organs for transplantation has been highlighted recently, accompanied by calls for changes in the law on consent to donation. ${ }^{14}$ In our study, though solid organs were donated from only 19 of 52 patients with brain stem death, in only three of the remaining 33 cases was consent for donation not requested. We suggest that failure to request donation after brain stem death is uncommon at our hospital. If this level of requesting donation is representative of that at most other centres then legislation to make request compulsory would not considerably increase the number of organs available for transplantation. Wakeford and Stepney, in a survey of attitudes to organ donation, concluded that coercive measures were less likely to increase the supply of donor organs than improved education of the public and the medical profession.

Sixteen organs were not used when consent to their removal had been granted because of lack of intensive care facilities or shortage of recipients matched for blood group and presence of cytomegalovirus. In this series organs from eight potential donors could not be used because the coroner would not release the body, a feature others have experienced with the procurator fiscal in Scotland (J D Miller, personal communication). The prevalence of traumatic causes of brain stem death suggests that this is a nationwide feature and is unlikely to change, though individual coroners and procurators fiscal have widely differing opinions on this subject, some releasing bodies when others would not.

Of concern is the large proportion (a quarter) of potential donors whose poor general condition rendered them unsuitable for donation. This, coupled with the high incidence of complications, means that such patients require careful medical and nursing care with particular attention to cardiovascular function. Perhaps by attention to these factors not only would absolute numbers of donors increase but there would also be an improvement in the condition of organs that are donated.

We thank our neurosurgical, neuroanaesthetic, and other medical colleagues and the Cambridge transplant coordinators for their cooperation with the collection of this information.

\footnotetext{
1 Chisholm GD. Time to end the softly softly approach on harvesting organs for transplantation. Br.Med f 1988:296:1419-20.

transplantation. Br. Med $1988: 296: 1419-20$.
Jennett B. Hessett $C$. Brain death in Britain as reflected in renal donors.

2 Jennett B, Hessett C. Brain death in Britain as reflected in renal donors.
Br.Med f $1981 ; 283: 359-62$.
3 Department of Health and Social Security Cudaveric organs for transplantation; a code of practice including the diagnosis of hrain death. London: HMSO, 1983. 4 Rudge CJ. Consent for transplants. Br F Hosp Med 1987;38:93-4.

5 Wakeford RE, Stepney R. Obstacles to organ donation. Br F Surg 1989:76: $435-9$.

(Accepted 9 August 1989,
}

\title{
Dipstick haematuria and bladder cancer in men over 60: results of a community study
}

\author{
J Philip Britton, Anthony C Dowell, Peter Whelan
}

Abstract

Objective-To investigate the prevalence and relevance of dipstick haematuria in a group of men in the community.

Design-Prospective study of elderly men invited to attend a health centre for urine screening as part of a health check.

Setting-An inner city health centre in Leeds.

Subjects -578 of 855 men aged $60-85$ responding to an invitation to participate.

Interventions-The subjects had their urine tested with a dipstick (Multistix) for the presence of blood and then tested their urine once a week for the next 10 weeks. Those with one or more positive test results were offered full urological investigation.

Main outcome measure-The prevalence of St James's University
Hospital, Leeds LS9 7TF J Philip Britton, FRCS, tutor and honorary registrar in urology

Anthony C Dowell, MRCGP, lecturer in general practice

Peter Whelan, FRCS,

consultant urologist

Correspondence to: Mr Whelan.

BrMed f 1989;299:1010-2 with appreciable urological disease. The introduction of less invasive methods of investigation, particularly flexible cystoscopy and ultrasonography, has made investigation of these patients simple and safe and makes screening for bladder cancer in the community more feasible.

\section{Introduction}

Urine dipsticks are widely used in health screening clinics,' in occupational health departments, and in routine clinical practice. ${ }^{2}$ Asymptomatic occult urinary bleeding is a common finding. Its prevalence in elderly men ranges from $4 \%$ to $13 \%$, ${ }^{3.6}$ and the reported incidence of associated urological abnormality varies from $40 \%$ to $100 \% .^{13.4}$ The need for and extent of investigation of such a finding, however, remains controversial. ${ }^{31011}$

The importance of investigating microscopic haematuria lies in the possibility of diagnosing urological malignancy at an early stage, especially bladder cancer. Bladder cancer is the fourth commonest malignancy in men, with an annual registration rate for men over the age of 60 in Yorkshire of 1.5 per 1000 (Yorkshire Regional Cancer Register). We report the results of a screening programme to investigate the prevalence and relevance of dipstick haematuria in a 
group of men in the community aged $60-85$ and examine the ability of urine dipsticks to detect bladder cancer in these patients.

\section{Patients and methods}

Nine hundred and forty two men aged $60-85$ were identified from the age and sex register of seven general practitioners working in one inner city health centre in Leeds. Patients currently under the care of a urologist and those considered to be unfit to attend the health centre $(87$ men) were excluded. The remaining 855 men were invited to attend the health centre for a health check, to include measurement of blood pressure and urine tests for blood, glucose, and protein. Only one invitation was sent and the nonresponders were not pursued.

All attenders were seen by one nursing sister. A freshly voided sample of urine was tested with Multistix 10 SG and all subjects were asked to test their urine once a week with Hemastix for 10 weeks.

All subjects with dipstick haematuria were assessed by one member of the urology team (JPB). Evaluation included a history and examination, repeat dipstick urine analysis, urine microscopy and culture, urine cytology, full blood count, serum biochemistry, intravenous urography or renal ultrasonography, or both, and cystoscopy. During cystoscopy visible abnormalities were biopsied; random mucosal biopsies were carried out only on patients with atypical cytological findings.

\section{Results}

The 855 invitations resulted in 578 men $(68 \%)$ attending the health centre to participate in the

TABLE I $-A g$ ge groups of men screened

\begin{tabular}{lrrrrr}
\hline & \multicolumn{5}{c}{ Age (years) } \\
\cline { 2 - 6 } & $60-64$ & $65-69$ & $70-74$ & $75-79$ & $80-85$ \\
\hline No $(\%)$ of attenders $(\mathrm{n}=578)$ & $171(20)$ & $\begin{array}{r}159(19) \\
\text { No }(\%) \text { of non-attenders }(\mathrm{n}=277)\end{array}$ & $\begin{array}{r}114(13) \\
42(11)\end{array}$ & $\begin{array}{c}91(11) \\
43(5)\end{array}$ & $\begin{array}{c}43(5) \\
21(2)\end{array}$ \\
\hline Total $(\mathrm{n}=855)$ & $267(31)$ & $234(28)$ & $156(18)$ & $134(16)$ & $64(7)$ \\
\hline
\end{tabular}

TABLE II - Results of initial dipstick test by age

\begin{tabular}{lcccccc}
\hline & \multicolumn{5}{c}{ Dipstick test result } \\
\cline { 2 - 7 } & Negative & Non-haemolysed trace & Hacmolysed trace & + & ++ & +++ \\
\hline No of men aged 60-69 & 289 & 20 & 17 & 4 & 0 & 0 \\
No of men aged 70-85 & 211 & 15 & 14 & 3 & 3 & 2 \\
\hline
\end{tabular}

TABLE III - Findings in 61 men investigated

\begin{tabular}{lc|lc}
\hline & No of men & & No of men \\
\hline Bladder tumour & 4 & Glomerulonephropathy & 8 \\
Prostatic cancer & 1 & Renal calcification & 4 \\
Epithelial dysplasia & 5 & Renal cyst & 5 \\
Inverted papilloma & 1 & Pelviureteric junction obstruction & 1 \\
Chronic bladder inflammation & 3 & & \\
Urine infection & 2 & Bulbar urethral stricture & 4 \\
Bladder stones & 4 & Severe outflow obstruction & 1 \\
\hline
\end{tabular}

TABLE IV - Findings in 26 men investigated

\begin{tabular}{lc|lc}
\hline & No of men & & No of men \\
\hline Epithelial dysplasia & 2 & Chronic retention with bilateral & 1 \\
Bladder haemangioma & 1 & hydronephrosis & 1 \\
Urine infection & 1 & Severe phimosis & 1 \\
Bladder stones & 2 & Urethral diverticulum & \\
Glomerulonephropathy & 1 & & \\
Renal calcification & 2 & & \\
Renal cyst & 1 & & \\
\hline
\end{tabular}

screening programme. Table I shows the age range of the attenders and non-attenders. The percentage attendance was similar in all age groups.

Seventy eight men $(13 \%)$ were found to have dipstick haematuria at their initial visit to the health centre (table II) and 61 agreed to further investigation. Thirty four were found to have urological abnormalities, and investigations showed nothing abnormal in 27; seven did not complete all investigations. Table III lists the findings in the 34 patients. More than one disorder was found in 10 patients.

Four patients (aged 61,63,64, and 72) with no history of visible bleeding were found to have a bladder tumour. One patient with an abnormal urine cytological picture had multiple bladder tumours (histological grade G2pT1) and three patients with a normal cytological picture had solitary tumours (histological grade GlpTa). In all four patients initial dipstick testing showed only a trace of blood and the haematuria was intermittent on the 10 weekly tests. Microscopy identified red cells in three out of four.

Four hundred and fourteen men whose initial urine test result at the health centre had been negative returned the results of their weekly tests at the end of 10 weeks. Fifty four men had one or more positive results for blood and 26 agreed to investigation. Eleven were found to have urological disease (table IV), and investigations showed nothing abnormal in 15; four did not complete all investigations.

\section{Discussion}

This study found dipstick haematuria in $132(23 \%)$ of 578 men aged $60-85$ in an inner city community -78 $(13 \%)$ detected by a single dipstick test and $54(9 \%)$ identified by repeated tests performed over 10 weeks. Dipstick haematuria was intermittent in three quarters of cases, showing the value of repeated tests and emphasising the importance of not ignoring a positive result when a subsequent one is negative. After instruction patients had no difficulty in using or reading the urine dipsticks.

Urine dipsticks have been shown to provide an accurate method of detecting red cells in urine when compared with phase contrast microscopy ${ }^{12}$ and offer a convenient and cost effective means of detecting microscopic haematuria when screening a large population. ${ }^{13}$ In this study comparing the dipstick result with that on light microscopy in 58 patients at the time of outpatient assessment yielded 11 false positive and two false negative results, assuming two or more red cells per high power field to be abnormal. ${ }^{1+}$ Identifying red cells by simple light microscopy may be difficult, however, and indeed disease was found in eight patients with a false positive result.

Of the 87 men investigated, 45 were found to have urological disease, confirming the need to investigate all patients with dipstick haematuria, irrespective of degree. No correlation was found between the degree of haematuria and the severity of the underlying cause, though no urological malignancies were discovered in those men found to have haematuria only on subsequent weekly tests. With the increasing accuracy of ultrasonography ${ }^{15}$ and the introduction of flexible cystourethroscopy carried out under local anaesthesia $^{16}{ }^{17}$ investigation of patients with dipstick haematuria is simple and safe. The number of patients in whom ureteric disease will be missed is very small and invasive procedures are avoided, particularly intravenous urography and rigid cystourethroscopy.

Early detection of bladder tumours by urine dipsticks was described 20 years $\mathrm{ago}^{18}$ and has since been shown in selected populations. ${ }^{13-10}$ In this community study we found four men with a bladder tumour and seven with epithelial dysplasia. Further 
disease may have been missed in those subjects who failed to attend for screening or who declined investigation once haematuria was found.

Our results show that urine dipsticks, by identifying a high risk group in the male community suitable for investigation, are capable of detecting important urological disease, including bladder cancer. The introduction of less invasive methods of investigation, particularly flexible cystourethroscopy, makes screening for bladder cancer in the community more feasible. The implications for an already overloaded urological service of detecting such a wealth of disease would, however, be enormous and the true value of early detection of cancer will be shown only by a long term controlled study.

We thank Mr P H Smith, Professor C M Harris, Sister Judith Mumford, the doctors and staff of Meanwood Group Practice, and the secretarial staff of the departments of urology and general practice for their help with this project. We also thank Leeds Family Practitioner Committee for its financial support and the Ames Division of Miles Laboratories Ltd for providing the urine dipsticks.

1 Ritchie CD, Bevan EA, Collier StJ. Importance of occult haematuria found at screening. Br Med f 1986;292:681-3.

2 Morgan AG. Is routine urine testing in outpatient clinics useful? Br Med 7 1988;297:1173.

3 Mohr DN, Offord KP, Owen RA, Melton LJ. Asymptomatic microhematuria and urologic disease. FAMA 1986;256:224-9.

\section{Non-biological factors in day to day variation of heparin requirements}

\section{A G Fennerty, M N Levine}

Department of Medicine, McMaster University, Hamilton, Ontario, Canada A G Fennerty, MD, senior registrar

M N Levine, $\operatorname{FRCP}(\mathrm{C})$ clinical trials scholar

Correspondence to:

Dr A G Fennerty,

Chest Clinic,

Southern General Hospital, Glasgow G51 4TF.

BrMed f 1989;299:1012-3 activated partial thromboplastin time should be main-
In the treatment of venous thromboembolic disease the tained within one and a half to two and a half times the control.' In practice this is difficult to achieve, with frequent day to day variation in the thromboplastin time, requiring regular changes in the dose of heparin. ${ }^{2}$ While some variation may be biological, we identified variables in the delivery and monitoring of a heparin infusion in our hospital, which might have influenced the thromboplastin time.

\section{Patients, methods, and results}

We monitored two positive pressure infusion devices used to deliver heparin. The IMED 960 (San Diego, California) was monitored on seven patients for 257 hours and the IVAC 560 (San Diego, California) on four patients for 112 hours. The median flow rate was $31 \mathrm{ml} / \mathrm{h}$ (range 20 to $50 \mathrm{ml} / \mathrm{h}$ ). The mean (SD) hourly error in the volume delivered as recorded by each pump was $9(6) \%$ for the IMED 960 and $15(9) \%$ for the IVAC 560 , with errors of $20 \%$ or more in $31(12 \%)$ and $22(20 \%)$ of the hourly observations, respectively. When pumps were unavailable heparin was delivered through a gravity feel roller clamp system, with a reservoir refilled hourly. According to ward charts all patients on this system received the prescribed hourly rate. When three subjects were monitored with a total of 34 random visits, however, coinciding with the midpoint of the hourly infusion, the mean (SD) hourly error calculated from the volume of fluid remaining in the reservoir was $57(9) \%$, with $100 \%$ of the infusion running through in less than 30 minutes in eight $(23 \%)$ observations. The reservoirs were sometimes left unfilled for up to one hour.
Thompson IM. The evaluation of microscopic hematuria: a population-based tudy, 7 Urol 1987;138:1189-90.

5 Messing EM, Young TB, Hunt VB, Emoto SE, Wehbie JM. The significance of asymptomatic microhematuria in men 50 or more years old: findings of ome screening study using urinary dipsticks. $\mathcal{f} U$ rol $1987 ; 137: 919-22$.

6 Haug K, Bakke A, Daae LNW, Gothlin J, Willasen Y. Screening for haematuria, glucosuria and proteinuria in people aged 55-64. Scand F Prim Health Care 1985;3:31-4.

7 Greene LF, O'Shaughnessy EJ, Hendricks ED. Study of five hundred patients with asymptomatic microhematuria. FAMA 1956;161:610-4.

Carson CC, Segura JW, Greene LF. Clinical importance of microhematuria. ЭAMA 1979;241:149-50.

Golin AL, Howard RS. Asymptomatic microscopic hematuria. $f$ Urol 1980;124:389-91.

10 Bullock N. Asymptomatic microscopical haematuria. Br Med f 1986;292:645.

11 Kassirer JP. The wild goose chase and the elephant's relevance. $\mathcal{F A M A}$ 1986;256:256-7.

12 Arm JP, Peile EB, Rainford DJ, Strike PW, Tettman RE. Significance of dipstick haematuria. 1. Correlation with microscopy of the urine. $B r f$ Urol $1986: 58: 211-7$.

13 Mariani AJ, Luangphinith S, Loo S, Scottolini A, Hodges CV. Dipstick chemical urinalysis: an accurate cost-effective screening test. $\mathcal{f}$ Urol 984;132:64-6

14 Carlton CE Jr, Scardino PT. Initial evaluation, including history, physical examination and urinalysis. In: Walsh PC, Gittes RF, Perlmutter AD Stamey TA, eds. Campbell's urology. Philadelphia: W B Saunders, 1986: 276-311.

15 Corwin HL, Silverstein MD. The diagnosis of neoplasia in patients with asymptomatic microscopic hematuria: a decision analysis. $f$ Urol 1988;139. $1002-5$

16 Powell PH, Manohar V, Ramsden PD, Hall RR. A flexible cytoscope. Brf Urol 1984;56:622-4

17 Flannigan GM, Gelister JSK, Noble JG, Milroy EJG. Rigid versus flexible cytoscopy. A controlled trial of patient tolerance. Brf Urol 1988;62:537-40.

18 Jameson RM. Early detection of urinary-tract malignancy by urine testing with reagent strips. Lancet 1969;i:1164.

(Accepted 8 August 1989)

After collection blood can be left for periods of up to 150 minutes before the thromboplastin time is measured. To assess the effect of this delay 12 patients had two samples of blood drawn consecutively into sodium citrate vacutainers. One was dispatched for immediate measurement, and the other was stored at room temperature and measured 90 to 150 minutes later (mean 113 minutes). There was a mean fall in the thromboplastin time of six seconds (table). Within sample variability of the measurement and the day to day variability with a standard heparinised sample was maintained at two seconds in our laboratory.

Effects of delay in measuring activated partial thromboplastin time in 12 patients

\begin{tabular}{|c|c|c|c|}
\hline \multicolumn{2}{|c|}{$\begin{array}{c}\text { Activated partial } \\
\text { thromboplastin time(s) }\end{array}$} & \multirow[b]{2}{*}{ Delay (mins) } & \multirow{2}{*}{$\begin{array}{c}\text { Change in } \\
\text { activated partial } \\
\text { thromboplastin time }(s)^{\star}\end{array}$} \\
\hline $\begin{array}{c}\text { Measured } \\
\text { immediately }\end{array}$ & $\begin{array}{l}\text { Measured } \\
\text { after delay }\end{array}$ & & \\
\hline 84 & 69 & 80 & -15 \\
\hline 69 & 72 & 90 & 3 \\
\hline 79 & 82 & 90 & 3 \\
\hline 76 & 57 & 90 & -19 \\
\hline 54 & 50 & 100 & -4 \\
\hline 52 & 50 & 110 & -2 \\
\hline 88 & 83 & 110 & -5 \\
\hline 71 & 65 & 120 & -6 \\
\hline 55 & 51 & 120 & -4 \\
\hline 43 & 54 & 150 & 11 \\
\hline 82 & 55 & 150 & -27 \\
\hline 54 & 44 & 150 & -10 \\
\hline
\end{tabular}

${ }^{\star}$ Mean (SD) change was $-6(10)$, two tailed paired $t$ test $\mathrm{p}=0 \cdot 62$.

\section{Comment}

Monitoring and adjusting heparin treatment assumes a steady rate of delivery; this is rarely the case. We have confirmed the considerable inaccuracy of a roller clamp system of infusion, ${ }^{3}$ which results in peaks and troughs of heparin activity. The IMED 960 is a fairly expensive pump and reported to have a mean hourly error of less than 5\%; while some other pumps on the market have errors well in excess of $10 \%{ }^{4}$; these figures, however, are based on in vitro laboratory tests. On busy wards pumps cannot be guaranteed the attention required for optimum performance, and accuracy may be compro- 